\title{
Impact of Magnetic Field on Pressures of Programmable Cerebrospinal Fluid Shunts: An Experimental Study
}

\author{
Idiris ALTUN ${ }^{1}$, Kasım Zafer YUKSEL ${ }^{1}$, Tufan MERT ${ }^{2}$ \\ ${ }^{1}$ Sutcu Imam University, Medical Faculty, Department of Neurosurgery, Kahramanmaras, Turkey \\ ${ }^{2}$ Sutcu Imam University, Medical Faculty, Department of Biophysics, Kahramanmaras, Turkey
}

\section{ABSTRACT}

AIM: To investigate whether programmable cerebrospinal fluid (CSF) shunts are influenced by exposure to the magnetic field and to compare the effects of magnetic field in 4 different brands of programmable CSF shunts.

MATERIAL and METHODS: This experimental study was performed in the laboratory using a novel design of magnetic field. Four types of programmable CSF shunts (Miethke $₫$, Medtronic $₫$, Sophysa $₫$ and Codman $₫$ Hakim $®$ ) were exposed to the magnetic field generated by an apparatus consisting of Helmholtz coil for 5 minutes. In every CSF shunt, initial pressures were adjusted to 110 mm $\mathrm{H}_{2} \mathrm{O}$ and pressures after exposure to magnetic field were noted. These measurements were implemented at frequencies of $5 \mathrm{~Hz}$, $20 \mathrm{~Hz}, 30 \mathrm{~Hz}, 40 \mathrm{~Hz}, 60 \mathrm{~Hz}$ and $80 \mathrm{~Hz}$. In each type, three shunts were utilized and evaluations were made twice for every shunt.

RESULTS: At 5, 30, 40 and $60 \mathrm{~Hz}$, Groups 1, 2 and 3 had significantly higher average pressures than Group 4 . At 20 and $80 \mathrm{~Hz}$, Groups 1 and 2 had notably different pressure values than Groups 3 and 4 . Group 3 displayed the highest pressure, while Group 4 demonstrated the lowest pressure.

CONCLUSION: Exposure to magnetic fields may affect the pressures of programmable CSF shunts. However, further controlled, clinical trials are warranted to elucidate the in-vivo effects of magnetic field exposure.

KEYWORDS: Hydrocephalus, Cerebrospinal fluid, Shunt, Magnetic field, Pressure

\section{INTRODUCTION}

$\mathrm{P}$ lacement of cerebrospinal fluid (CSF) shunt is the standard treatment of hydrocephalus. Shunt systems involve a valve to control pressure and to drain the CSF when the CSF pressure exceeds the previously set value of the valve. Pressure-adjustable shunt valves have a magnetic rotator and these shunts have been in use since the 1990s.

The optimal CSF diversion rate for an individual can be easily adjusted after shunt surgery by transcutaneous pressure setting using a magnetic device. But, environmental magnetic fields may change the intended pressure setting (8). A typical instance that necessitates caution is magnetic resonance imaging (MRI) examination, after which check- ing and re-programming of the shunt pressure setting has become a routine work for neurosurgeons. In addition, electromagnetic waves which are produced by cell phones may also affect medical devices such as CSF shunts and cardiac pacemakers. Therefore, use of cell phone in hospitals or in crowded trains should be restricted. Patients with adjustable shunt valves should be avoided of exposure to strong magnetic fields (9).

Contemporarily, there are several types of programmable and adjustable CSF valves available and all of these devices are dependent on a ball-on-spring valve mechanism that regulates CSF flow. These instruments use the principle of altering the tension of the spring with a magnetic rotor. Valves are programmed using a tool involving a strong external mag- 
net and therefore, these adjustable valves can be influenced via the magnetic field exposure. Since exposure to devices that generate magnetic field is very common and almost in daily life inevitable, the effects of these devices on settings of CSF shunts is vague (3). Previous studies indicated that even low-intensity external magnetic fields can result in significant changes for some types of programmable valves (9).

Thus, we designed this experimental study to assess the impacts of magnetic field on pressures of programmable CSF shunts at various frequencies. In this aim, 4 types of adjustable hydrocephalus shunts were used. Hopefully, results of the present study may aid in the elucidation of the possible impacts of magnetic fields on pressures in various types of programmable CSF shunts. These results may reinforce and pioneer conduction of further studies on this topic.

\section{- MATERIAL and METHODS}

\section{Study design}

This experimental study was carried out in the experimental laboratory of our institution. In order to test the impacts of exposure to the magnetic field, a novel design of pulse magnetic field (PMF) was adapted as shown in Figure 1. This PMF model has been initially described by Mert et al. (5).

This model utilizes a system with Helmholtz coils $60 \mathrm{~cm}$ in diameter that are placed $30 \mathrm{~cm}$ apart (6). The coils placed in a Faraday cage were connected to a signal generator (ILFA Electronic, Adana, Turkey) that produced a magnetic field with a peak amplitude of 1.5 milliTesla. The peak value of the magnetic field was measured by a gauss meter with a Halleffect probe (FW Bell model 6010, Sypris, Orlando, FL, USA). The time varying magnetic field consisted of a quasi-triangular waveform, with a rise time of $0.5 \mathrm{~ms}$ and a fall time of 9.5 ms. The induced electric field was a unipolar rectangular waveform with peak electric fields of $0.6 \mathrm{~V} / \mathrm{m}(0.59-0.61 \mathrm{~V} / \mathrm{m})$ between the coils (Figure 2) (5).

In this PMF model, a screw was used to attach the magnet to the bottom of the pendulum and this screw allowed changes in height between the magnet and the shunt ensuring the fixation of the distance. Extra lead weights not only provided the swing greater momentum, but also inhibited the interaction between the magnet of the swing and the magnetic device incorporated within the shunt itself.

In this experimental study, 4 different brands of programmable CSF shunts were exposed to the magnetic field generated by our apparatus described above coil for 5 minutes (Figure 3). Groups 1-4 were composed of Miethke ${ }^{\circledR}(B$. Braun Melsungen AG, Melsungen, Germany), Medtronic Strata ${ }^{\circledR}$ (Medtronic, Minessota, USA), Sophysa Sophy ${ }^{\circledR}$ (Sophysa, Orsay, France), and Codman $^{\circledR}$ Hakim $^{\circledR}$ (Codman Neuro, MA, USA) brands, respectively. In every CSF shunt, initial pressures were adjusted to $110 \mathrm{~mm} \mathrm{H}_{2} \mathrm{O}$ and pressures after an exposure to magnetic field for 5 minutes were noted. These measurements were implemented at frequencies of $5 \mathrm{~Hz}, 20 \mathrm{~Hz}, 30 \mathrm{~Hz}, 40 \mathrm{~Hz}$,

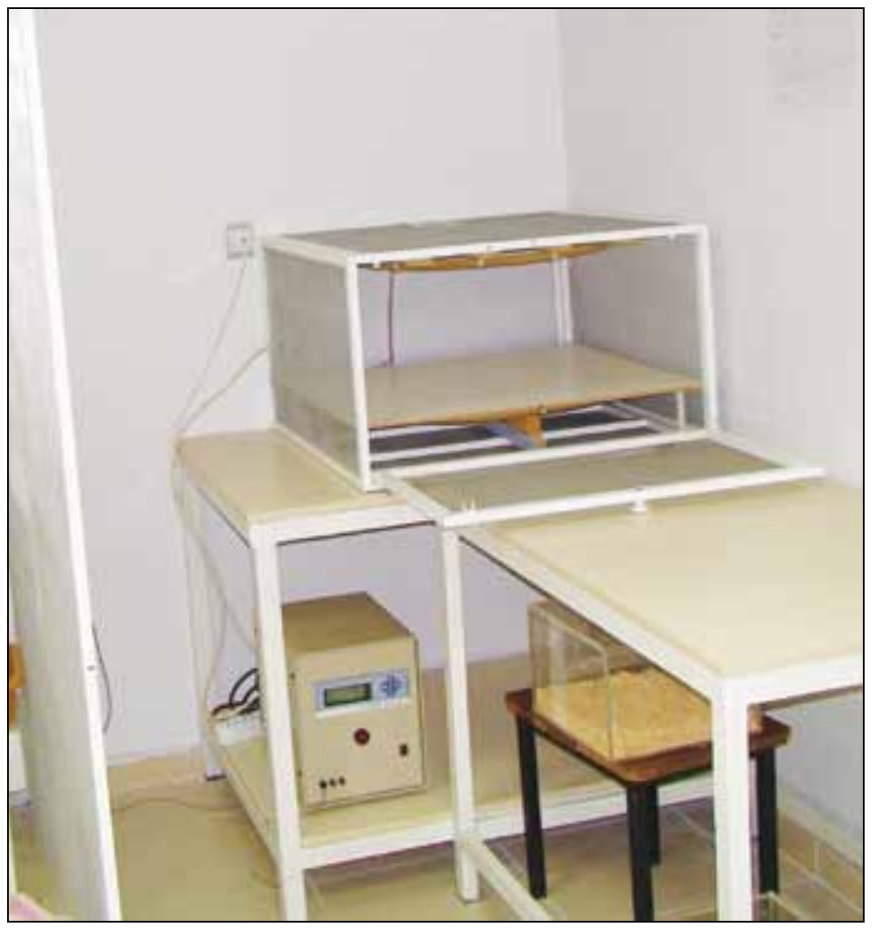

Figure 1: View of magnetic field system used in the study.

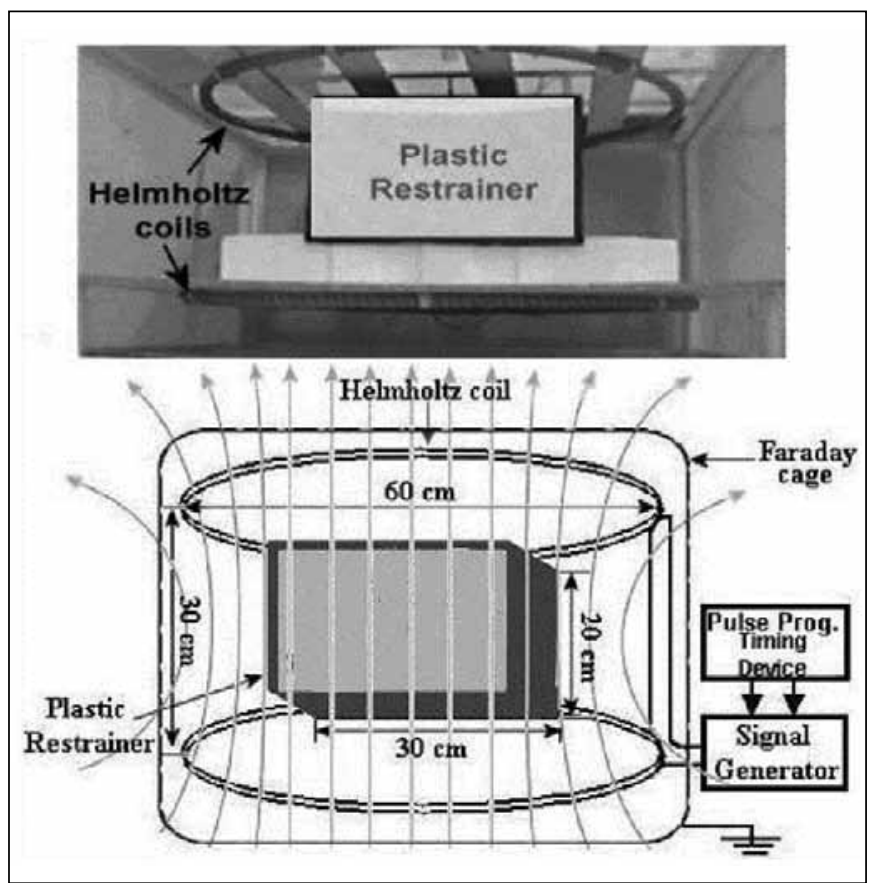

Figure 2: Pulsed magnetic field system used to test 4 different programmable CSF shunts at frequencies of $5 \mathrm{~Hz}, 20 \mathrm{~Hz}, 30 \mathrm{~Hz}$, $40 \mathrm{~Hz}, 60 \mathrm{~Hz}$ and $80 \mathrm{~Hz}$. Before every measurement, pressure was adjusted to $110 \mathrm{~mm} \mathrm{H}_{2} \mathrm{O}$ at the relevant frequency (This figure has been used with the permission of Mert $\mathrm{T}$, who has described this system initially in references 5 and 6). 


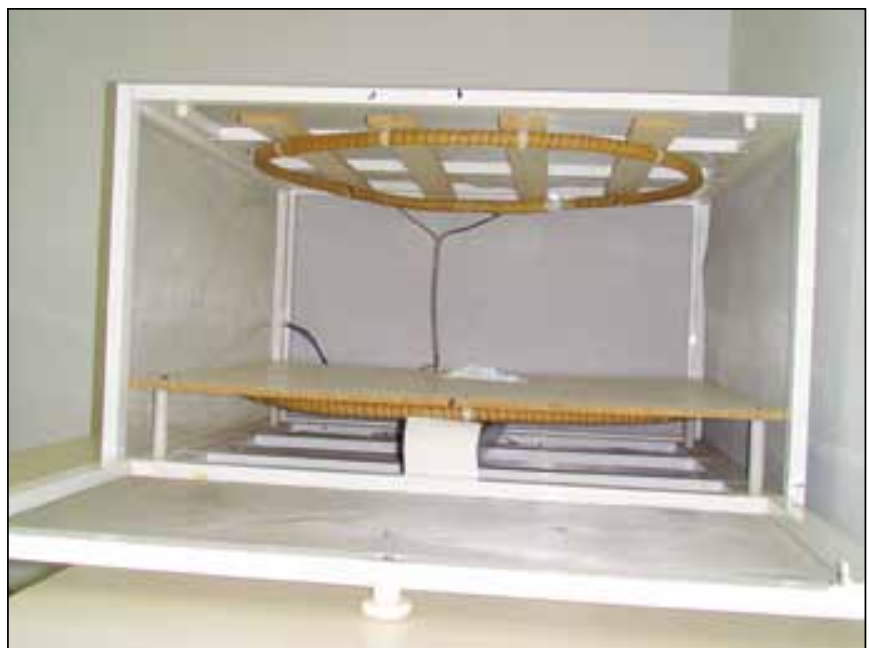

Figure 3: Four different brands of programmable CSF shunts were exposed to the magnetic field generated by our apparatus described above coil for 5 minutes.
$60 \mathrm{~Hz}$ and $80 \mathrm{~Hz}$. In each group, 3 shunts were utilized and evaluations were made twice for every shunt (Figure 4A-D).

Every shunt was investigated by means of the same rig and great care was taken to restore the identical conditions prior to every measurement. The shunt under investigation was mounted in the rig. Air bubbles were gently flushed out of the working fluid route, and the pressure transducer was calibrated prior to the infusion (3).

\section{Statistical Analysis}

Analysis of data was made using the IBM SPSS Statistics 20 program (SPSS Inc., Chicago, IL, USA). Since number of subjects was low in each group $(n=6)$, non-parametric methods were used in this purpose. Kruskal-Wallis test was used for comparison of variables. In case a significant difference was detected between groups, 2 groups were compared by means of Mann-Whitney $U$ test. Quantitaive variables are presented as mean, standard deviation and

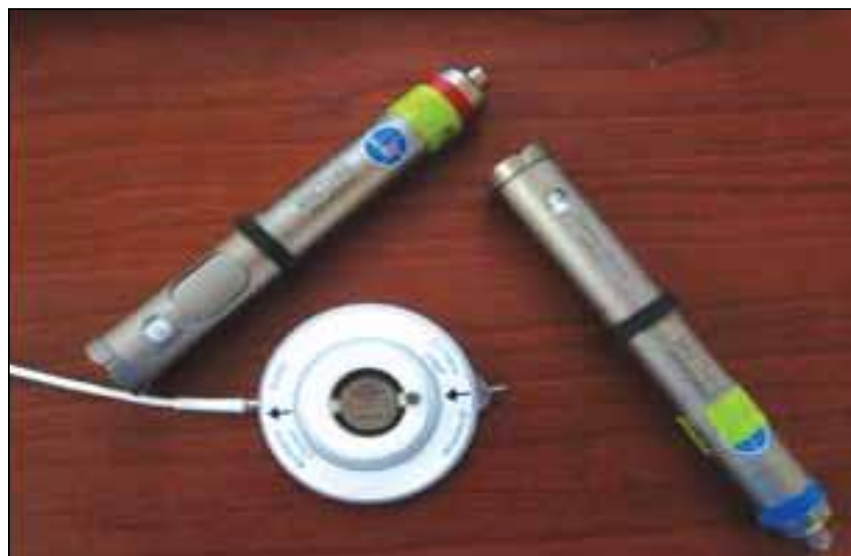

(A)

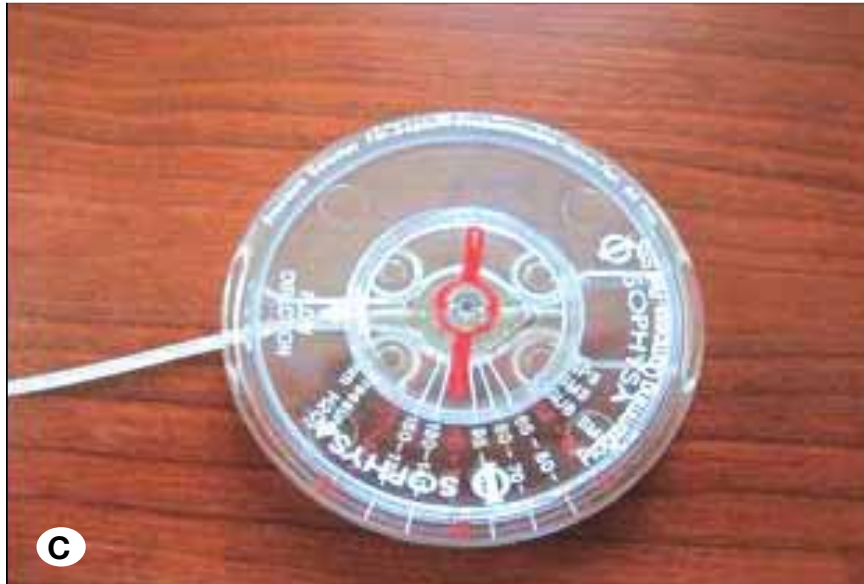

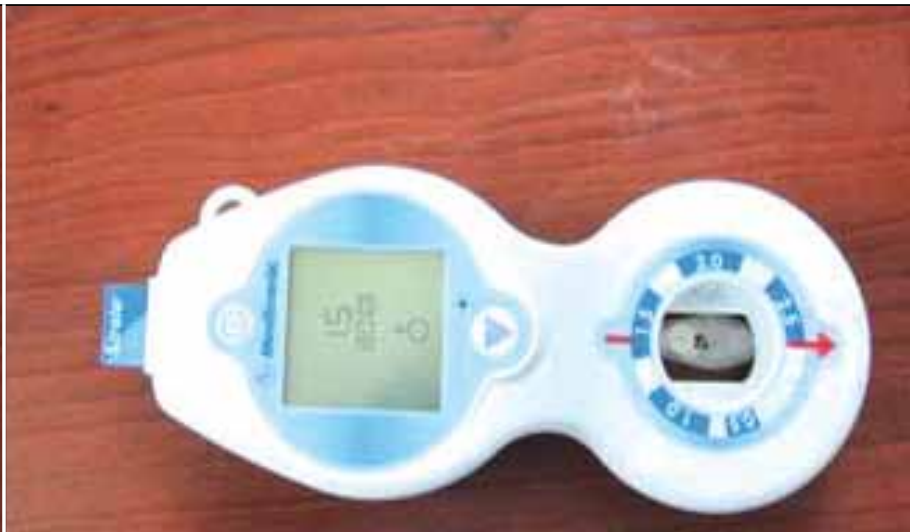

B

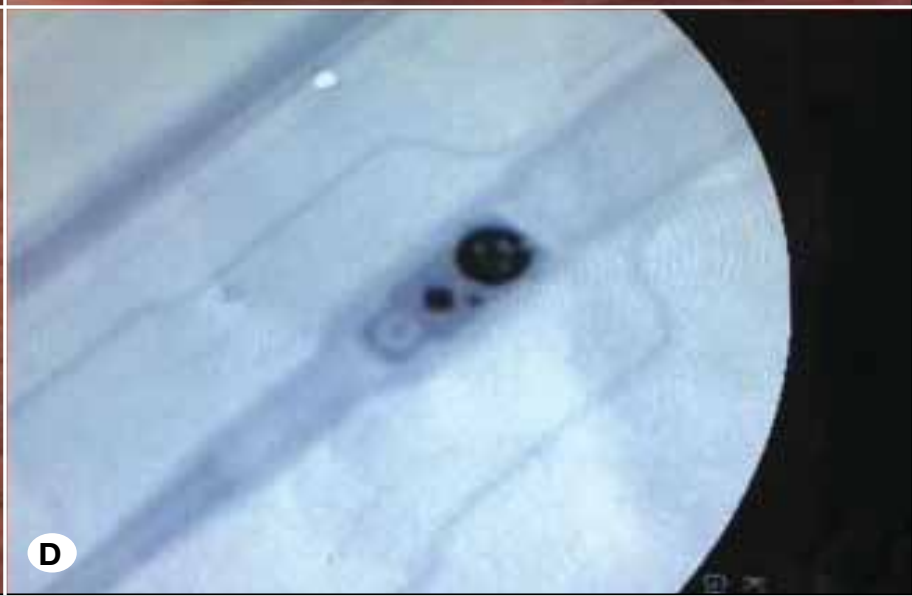

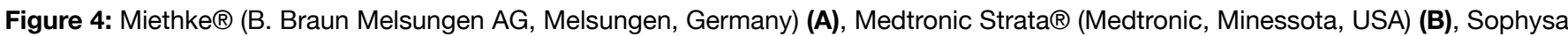
Sophy $\left(\right.$ (Sophysa, Orsay, France) (C), and Codman $®$ Hakim ${ }^{\circledR}$ (Codman Neuro, MA, USA) (D) brands, respectively. In every CSF shunt, initial pressures were adjusted to $110 \mathrm{~mm} \mathrm{H} \mathrm{H}_{2} \mathrm{O}$ and pressures after an exposure to magnetic field for 5 minutes were noted. These measurements were implemented at frequencies of $5 \mathrm{~Hz}, 20 \mathrm{~Hz}, 30 \mathrm{~Hz}, 40 \mathrm{~Hz}, 60 \mathrm{~Hz}$ and $80 \mathrm{~Hz}$. In each group, 3 shunts were utilized and evaluations were made twice for every shunt. 
median, interquartile range. Confidence interval was $95 \%$ and $p$ value $<0.05$ was considered as statistically significant.

\section{RESULTS}

An overview of measurements made in 4 groups after exposure to the experimental magnetic field model is presented in Table I. Pressure measurements are expressed in $\mathrm{mm} \mathrm{H}_{2} \mathrm{O}$ for each group.

Distribution of groups in homogeneous subsets at frequencies of $5 \mathrm{~Hz}, 20 \mathrm{~Hz}, 30 \mathrm{~Hz}, 40 \mathrm{~Hz}, 60 \mathrm{~Hz}$ and $80 \mathrm{~Hz}$ is shown in Table II.
Kruskal Wallis test performed seperately for all frequency values yielded remarkable differences in terms of pressures at various CSF shunt groups. Mann Whitney $U$ test was utilized to compare two groups and results are demonstrated in Table III. Accordingly;

At $5 \mathrm{~Hz}$, Groups 1, 2 and 3 had significantly higher average pressures than Group 4.

At $20 \mathrm{~Hz}$, Groups 1 and 2 had notably different pressure values than Groups 3 and 4. Group 3 displayed the highest pressure, while Group 4 demonstrated the lowest pressure.

At $30 \mathrm{~Hz}$, Groups 1, 2 and 3 had significantly higher average

Table I: An Overview of Pressure Measurements (in $\mathrm{mm} \mathrm{H}_{2} \mathrm{O}$ ) Performed in 4 Groups Following Exposure to the Experimental Magnetic Field Model. Magnetic Fields were Applied for 5 Minutes on Each Device and These Measurements Made Twice for Each Shunt were Expressed in $\mathrm{mm} \mathrm{H}_{2} \mathrm{O}$

\begin{tabular}{|c|c|c|c|c|c|c|c|}
\hline \multirow{2}{*}{$\begin{array}{l}\text { Experimental } \\
\text { Group }\end{array}$} & \multirow{2}{*}{$\begin{array}{l}\text { Measurement } \\
\text { number }\end{array}$} & \multicolumn{6}{|c|}{ Frequency (Hz) } \\
\hline & & 5 & 20 & 30 & 40 & 60 & 80 \\
\hline \multirow{6}{*}{1} & 1 & 0.5 & 0 & 1 & 5 & 2 & 2 \\
\hline & 2 & 1 & 2 & 1 & 3 & 2 & 2 \\
\hline & 3 & 0 & 1.5 & 2 & 4 & 2 & 2 \\
\hline & 4 & 1 & 1 & 1 & 2 & 2 & 2 \\
\hline & 5 & 0.5 & 1.5 & 2 & 2.5 & 2 & 1.5 \\
\hline & 6 & 1 & 2 & 1.5 & 2 & 2 & 1.5 \\
\hline \multirow{6}{*}{2} & 1 & 1 & 1 & 2 & 5 & 2 & 2 \\
\hline & 2 & 0.5 & 1.5 & 2 & 4 & 1.5 & 3 \\
\hline & 3 & 0.5 & 1 & 1 & 2 & 1 & 3 \\
\hline & 4 & 1 & 1 & 1 & 3 & 3 & 1 \\
\hline & 5 & 0 & 2 & 0 & 1 & 1.5 & 1.5 \\
\hline & 6 & 0 & 0 & 1 & 2 & 1.5 & 0.5 \\
\hline \multirow{6}{*}{3} & 1 & 1.5 & 3 & 2 & 5 & 1 & 2 \\
\hline & 2 & 2 & 2 & 2.5 & 3 & 1 & 4 \\
\hline & 3 & 1 & 3 & 2 & 2 & 3 & 3 \\
\hline & 4 & 0 & 2 & 1 & 2 & 2 & 3 \\
\hline & 5 & 1 & 1.5 & 2 & 3 & 2 & 3 \\
\hline & 6 & 0.5 & 2 & 1 & 2 & 1.5 & 3 \\
\hline \multirow{6}{*}{4} & 1 & 0 & 0 & 0 & 0 & 0 & 0 \\
\hline & 2 & 0 & 0 & 0 & 0 & 0 & 0 \\
\hline & 3 & 0 & 0 & 0 & 0 & 0 & 0 \\
\hline & 4 & 0 & 0 & 0 & 0 & 0 & 0 \\
\hline & 5 & 0 & 0 & 0 & 0 & 0 & 0 \\
\hline & 6 & 6 & 0 & 0 & 0 & 0 & 0 \\
\hline
\end{tabular}

Hint: Groups 1-4 were composed of Miethke ${ }^{\circledR}$ (B. Braun Melsungen AG, Melsungen, Germany), Medtronic Strata ${ }^{\circledR}$ (Medtronic, Minessota, USA), Sophysa Sophy ${ }^{\circledR}$ (Sophysa, Orsay, France), and Codman ${ }^{\circledR}$ Hakim $^{\circledR}$ (Codman Neuro, MA, USA) shunt brands, respectively. 
Table II: Distribution of Groups in Homogeneous Subsets at Various Frequencies

\begin{tabular}{|c|c|c|c|c|}
\hline \multirow{2}{*}{ Frequency (Hz) } & \multirow{2}{*}{ Groups } & \multicolumn{3}{|c|}{ Homogeneous subsets } \\
\hline & & 1 & 2 & 3 \\
\hline \multirow{4}{*}{5} & 1 & * & & \\
\hline & 2 & * & & \\
\hline & 3 & * & & \\
\hline & 4 & & * & \\
\hline \multirow{4}{*}{20} & 1 & * & & \\
\hline & 2 & * & & \\
\hline & 3 & & * & \\
\hline & 4 & & & * \\
\hline \multirow{4}{*}{30} & 1 & * & & \\
\hline & 2 & * & & \\
\hline & 3 & * & & \\
\hline & 4 & & * & \\
\hline \multirow{4}{*}{40} & 1 & * & & \\
\hline & 2 & * & & \\
\hline & 3 & * & & \\
\hline & 4 & & * & \\
\hline \multirow{4}{*}{60} & 1 & * & & \\
\hline & 2 & * & & \\
\hline & 3 & * & & \\
\hline & 4 & & * & \\
\hline \multirow{4}{*}{80} & 1 & * & & \\
\hline & 2 & * & & \\
\hline & 3 & & * & \\
\hline & 4 & & & * \\
\hline
\end{tabular}

Hint: Groups 1-4 were composed of Miethke ${ }^{\circledR}$ (B. Braun Melsungen AG, Melsungen, Germany), Medtronic Strata ${ }^{\circledR}$ (Medtronic, Minessota, USA), Sophysa Sophy ${ }^{\circledR}$ (Sophysa, Orsay, France), and Codman ${ }^{\circledR}$ Hakim $^{\circledR}$ (Codman Neuro, MA, USA) shunt brands, respectively.

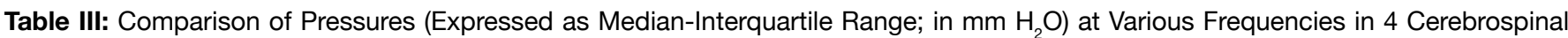
Fluid Shunt Groups Under Investigation

\begin{tabular}{|c|c|c|c|c|c|}
\hline \multirow{2}{*}{$\begin{array}{c}\text { Frequency } \\
(\mathbf{H z})\end{array}$} & \multicolumn{4}{|c|}{ Groups } & \multirow{2}{*}{ p-value } \\
\hline & 1 & 2 & 3 & 4 & \\
\hline 5 & $0.750-0.625$ & $0.500-1.000$ & $1.000-1.250$ & $0.000-0.000$ & $0.016^{\star}$ \\
\hline 20 & $1.500-1.250$ & $1.000-0.875$ & $2.000-1.125$ & $0.000-0.000$ & $0.001^{*}$ \\
\hline 30 & $1.250-1.000$ & $1.000-1.250$ & $2.000-1.125$ & $0.000-0.000$ & $0.003^{\star}$ \\
\hline 40 & $2.750-2.250$ & $2.500-2.500$ & $2.500-1.500$ & $0.000-0.000$ & $0.003^{\star}$ \\
\hline 60 & $2.000-0.000$ & $1.500-0.875$ & $1.750-1.250$ & $0.000-0.000$ & $0.002^{*}$ \\
\hline 80 & $2.000-0.500$ & $1.750-2.125$ & $3.000-0.500$ & $0.000-0.000$ & $0.001^{*}$ \\
\hline
\end{tabular}

Hint: *: statistically significant; Groups 1-4 were composed of Miethke ${ }^{\circledR}$ (B. Braun Melsungen AG, Melsungen, Germany), Medtronic Strata ${ }^{\circledR}$ (Medtronic, Minessota, USA), Sophysa Sophy ${ }^{\circledR}$ (Sophysa, Orsay, France), and Codman ${ }^{\circledR}$ Hakim $^{\circledR}$ (Codman Neuro, MA, USA) shunt brands, respectively. 
pressures than Group 4.

At $40 \mathrm{~Hz}$, Groups 1, 2 and 3 had significantly higher average pressures than Group 4.

At $60 \mathrm{~Hz}$, Groups 1, 2 and 3 had significantly higher average pressures than Group 4.

At $80 \mathrm{~Hz}$, Groups 1 and 2 had notably different pressure values than Groups 3 and 4. Group 3 displayed the highest pressure, while Group 4 demonstrated the lowest pressure.

\section{DISCUSSION}

The objective of the present study was to assess the alterations of pressures in several types of programmable CSF shunts due to magnetic field exposure at a novel experimental setting. Our results yielded that magnetic fields may lead significant changes in the shunt pressures and different types of shunts exhibit variable vulnerability after exposure to the magnetic fields.

There have been multiple reports on alteration of adjustable valve settings due to environmental magnetic field exposure $(1,10,11)$. In addition to the well-known effect of MRI magnets on programmable valve settings, lower intensity magnetic fields induced by magnetic toys, televisions, and speakers have been reported $(1,7)$. Studies assessing the in vivo settings of programmable valves have indicatedspontaneous changes in valve settings (10).

Both low-intensity and strong magnetic fields possess the risk for interaction with magnets utilized in adjustable and this interaction can be an important safety concern (3). It has been demonstrated that majority of nonferromagnetic metallic implants are safe for MRI procedures particularly if the magnetic torque is acceptably low (4). Nevertheless, there is scarce data on the safety of MRI procedure in patients with a programmable CSF shunt. The main risk for such a patient may be related to pressure changes, resetting and possible heating and dislodgment of the implant during the procedure. In addition, shunt valves can generate considerable artifacts and invalidate the imaging procedure itself. Since $\mathrm{MRI}$ is an important diagnostic measure during the follow-up of hydrocephalic patients, the compatibility features of various programmable CSF shunts might affect the choice of a particular model. Therefore, we compared the susceptibility of 4 different types of CSF shunts to magnetic field exposure in the present study. Analysis of our results has shown that Codman $^{\circledR}$ Hakim $^{\circledR}$ CSF shunts had the lowest pressures at all frequencies after being exposed to the magnetic field. On the other hand, Miethke ${ }^{\circledR}$ CSF shunt exhibited the highest pressure values while Medtronic ${ }^{\circledR}$ and Sophysa Sophy ${ }^{\circledR}$ were affected similarly.

In the literature, a publication investigating the effects of cell phones on the pressure setting of shunt valves indicated that the Sophy valve was safer than the other valves in the presence of environmental magnetic fields. Since the magnetic flux density decreases in inverse proportion to the square of the distance from the magnetic pole, shunt valves should not be implanted in close proximity to the ear (8).

Even though introduction of adjustable shunts was considered as an improvement in the management of hydrocephalus, undesirable effects of magnetic field exposure must be remembered (2). In a recent trial, Codman ${ }^{\circledR}$ Hakim $^{\circledR}$ and Miethke ${ }^{\circledR}$ programmable devices were found to be compatible with MR imaging with frankly negligible mechanical magnetic interactions (3). The Medtronic Strata ${ }^{\circledR}$ valve displayed intermediate performance and Sophy was not at risk for being reset due to exposure to magnetic field, whereas Sophysa Sophy $®$ exhibited strong magnetic field interactions even though the values were considered as safe after implantation (3).

Our results confirmed the compatibility of Codman ${ }^{\circledR}$ Hakim $^{\circledR}$ programmable shunts which also has similar after exposure pressure values. However, Miethke ${ }^{\circledR}$ shunts were likely to be influenced by magnetic field. Even though validation and reproducibility of our magnetic field model may be somewhat limited, we suggest that our results emphasize that selection of the appropriate type of shunt is a critical point for proper functioning.

Our novel design for producing an experimental magnetic field constitutes is another noteworthy point of this study. Hopefully, this model can be safely and effectively used in further trials implemented to assess the impact of magnetic field on many physiological and biological processes. Attributed to ethical considerations, testing the outcomes of magnetic field exposure cannot be feasible. Thus, we suggest that the model developed for the present trial can be used effectively after confirmation of its validity and reproducibility.

Limitations of our study are experimental design, technical restrictions and small number of shunts tested by means of this method. There may be multiple in-vivo factors which may alter the results observed under experimental conditions. Therefore, outcomes and conclusions mentioned in the current study must be interpreted with caution. Both manufacturers and relevant physicians must be aware of the impacts of magnetic fields on CSF shunt pressures.

\section{- CONCLUSION}

Pressures in programmable CSF shunts may be influenced remarkably owing to magnetic field exposure. Therefore, selection of the appropriate type of shunt may be an important issue for proper functioning after placement of the programmable CSF shunt. Further trials must be performed to elucidate the necessity of avoidance of exposure to magnetic field in patients with programmable CSF shunts.

\section{- REFERENCES}

1. Anderson RC, Walker ML, Viner JM, Kestle JR: Adjustment and malfunction of a programmable valve after exposure to toy magnets. Case report. J Neurosurg 101: 222-225, 2004

2. Jandial R, Aryan HE, Hughes SA, Levy ML: Effect of vagus nerve stimulator magnet on programmable shunt settings. Neurosurgery 55: 627-629, 2004 
3. Lavinio A, Harding S, Van Der Boogaard F, Czosnyka M, Smielewski P, Richards HK, Pickard JD, Czosnyka ZH: Magnetic field interactions in adjustable hydrocephalus shunts. $J$ Neurosurg Pediatrics 2:222-228, 2008

4. Lindner D, Preul C, Trantakis C, Moeller H, Meixensberger J: Effect of 3T MRI on the function of shunt valves-evaluation of Paedi GAV, Dual Switch and proGAV. Eur J Radiol 56: 56-59, 2005

5. Mert T, Altun I, Celik A, Surer T, Gunay I: Modulation of cytokine levels in ameliorative effects of pulsed magnetic field on an experimental model of Chronic Constriction Injury. Int $\mathrm{J}$ Radiat Biol 91: 596-602, 2015

6. Mert T, Ocal I, Gunay I: Pain relieving effects of pulsed magnetic fields in a rat model of carrageenan-induced hindpaw inflammation. Int J Radiat Biol 90:95-103, 2014
7. Miwa K, Kondo H, Sakai N: Pressure changes observed in Codman-Medos programmable valves following magnetic exposure and filliping. Childs Nerv Syst 17:150-153, 2001

8. Nomura S, Fujisawa H, Suzuki M: Effect of cell phone magnetic fields on adjustable cerebrospinal fluid shunt valves. Surg Neurol 63:467-468, 2005

9. Schneider T, Knauff U, Nitsch J, Firsching R: Electromagnetic field hazards involving adjustable shunt valves in hydrocephalus. J Neurosurg 96: 331-334, 2002

10. Sprung C, Schlosser HG, Lemcke J, Meier U, Messing-Jünger M, Trost HA, Weber F, Schul C, Rohde V, Ludwig HC, Höpfner J, Sepehrnia A, Mirzayan MJ, Krauss JK: The adjustable proGAV shunt: A prospective safety and reliability multicenter study. Neurosurgery 66:465-474, 2010

11. Strahle J, Selzer BJ, Muraszko KM, Garton HJL, Maher CO: Programmable shunt valve affected by exposure to a tablet computer. J Neurosurg Pediatrics 10:118-120, 2012 